\title{
Exploring the Role of Communication Media in the Informing Science Model: An Information Technology Project Management Perspective
}

\author{
April H. Reed \\ East Carolina University, \\ Greenville, NC, USA
}

\author{
Linda V. Knight \\ DePaul University, \\ Chicago, IL, USA
}

reeda@ecu.edu

lknight@cdm.depaul.edu

\begin{abstract}
This investigation expands understanding of the role of the medium or communication channel in the Informing Science framework by examining the domain of Information Technology project risk. IT projects provide a rich domain for exploring and expanding our understanding of Informing Science because IT project team members often have little or no prior work history together and thus few or no pre-existing social relationships and established communication patterns. Through exploration of this domain, we expand the traditional Informing Science model for routine communications to include a more thorough consideration of the role of the communication channel or medium. In the process, we also lessen the gap between the traditional informing science model and the related model for complex, non-routine communication.
\end{abstract}

Keywords: communication, Informing Science, complexity, non-routine communication, medium, channel, communications pathway, computer mediated communication, $\mathrm{CMC}$, media richness, social presence, project risk, virtual team, traditional team, co-located team, project management.

\section{Introduction}

The goal of this paper is to expand understanding of the role of the medium or communication channel in the Informing Science framework. To achieve this goal, we explore prior research applying to the domain of Information Technology project risk related to communication. This domain can provide particular insight into communication, since such project teams tend to be more extreme in their nature than traditional work groups. For example, development of social relationships, including trust building within the project group, is more challenging in project groups than in other typical organizational work groups because of the transitory nature of project teams. In a project, a team is assembled for the express purpose of completing a specific project,

Material published as part of this publication, either on-line or in print, is copyrighted by the Informing Science Institute. Permission to make digital or paper copy of part or all of these works for personal or classroom use is granted without fee provided that the copies are not made or distributed for profit or commercial advantage AND that copies 1) bear this notice in full and 2) give the full citation on the first page. It is permissible to abstract these works so long as credit is given. To copy in all other cases or to republish or to post on a server or to redistribute to lists requires specific permission and payment of a fee. Contact Publisher@InformingScience.org to request redistribution permission. i.e., "creating a unique product, service or result" instead of performing operational or routine work (Project Management Institute, 2008). Project team members may or may not have prior experience with any or all other project team members. They may or may not ever interact again with other team members after the end of the project. These differences can create additional barriers to building trust among 
team members. Further, the building of such trust is even more difficult on virtual project teams, when team members are not located in the same area and face-to-face communications are difficult or impossible.

In the Background section of this paper, we lay the foundation for our work by examining two Informing Science models (for traditional and complex communications), primary research into IT-related Communication, and research into Information Technology (IT) project risk. We then discuss how these areas relate. We specifically consider how the distinctions between traditional and virtual IT projects further enlighten and expand the Informing Science models. We conclude with implications and projections for the future.

\section{Background}

\section{Informing Science Theory}

\section{Informing Science model for routine communication}

The Informing Science framework of communication, shown in Figure 1, depicts both individual and compound complexities involved in communication, as well as the possible sources of such complexity (Cohen, 2009). The model breaks down communication into three distinct components: (1) the informer, (2) the medium, also referred to as the channel or communications pathway, and (3) the client/receiver of the communication (Cohen, 2009). Each component has its own limitations, which may impact the quality of some aspect of the communication. Together, the impacts on the components can create a compound effect, greatly increasing the limitations and reducing the effectiveness of the communication as a whole.

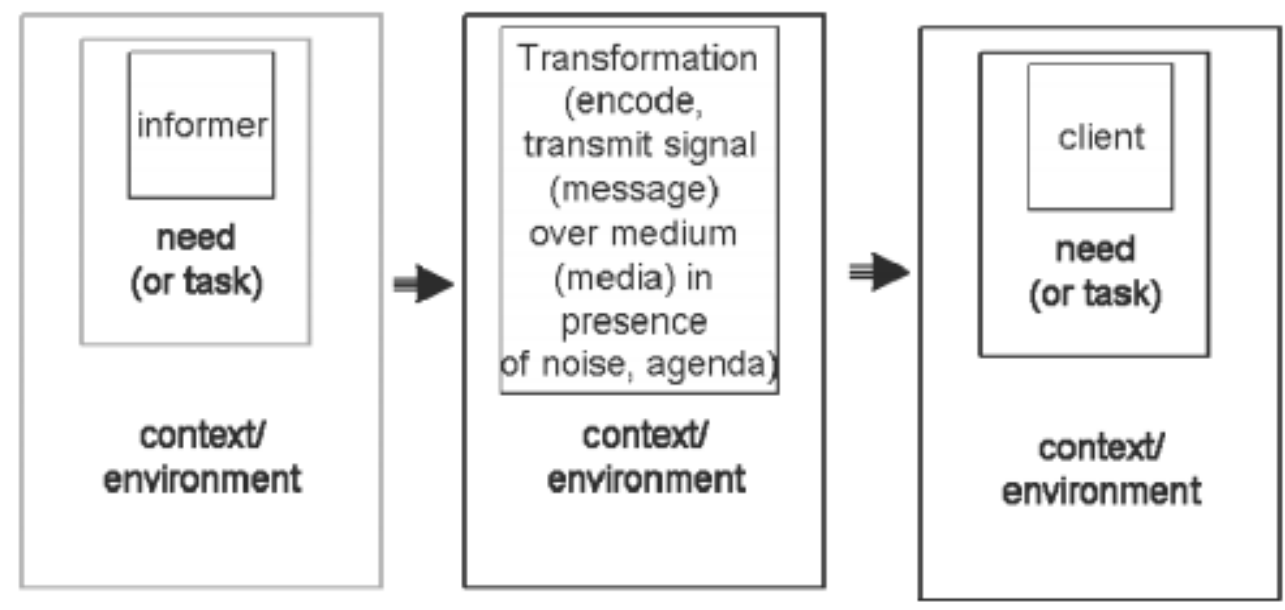

Figure 1 - Informing Science Communication Framework (Cohen 2009)

Prior researchers have explored the traditional Informing Science model for routine communication and extended the research on the complexities of the client/receiver component (Birdsall, 2009, Gill \& Bhattacherjee, 2007; Gill \& Hicks, 2006; Knight, Steinbach, \& Hop, 2012). This paper seeks to take a similar approach but focuses on the communication medium instead of the informer or the client. The medium or channel is composed of many elements: a) the encoded message, b) the transfer method, c) the surrounding noise, and d) the context or environment. The involvement of these multiple elements increases complexity and necessitates parallel consideration of the Informing Science model for complex, non-routine communication. 


\section{Informing Science model for complex, non-routine communication}

The routine/non-routine framework was created because of the many exceptions to the original Informing Science communication model (Gill \& Cohen, 2009). Gill developed a framework, shown in Figure 2, showing the placement of routine and non-routine communications along two dimensions, sender knowledge of existing client models, and complexity of the information being conveyed (Gill, 2010). These two variables are based on two sources of project risk identified by Cash, McFaran, and McKenney. (1988): experience with the technology and project structure. Gill (2010) extends these two concepts into "two distinct dimensions to informing." Experience with the technology is broadened to encompass knowledge of the client "mental models" (i.e. client characteristics and personality) while project structure becomes complexity of the communication content.

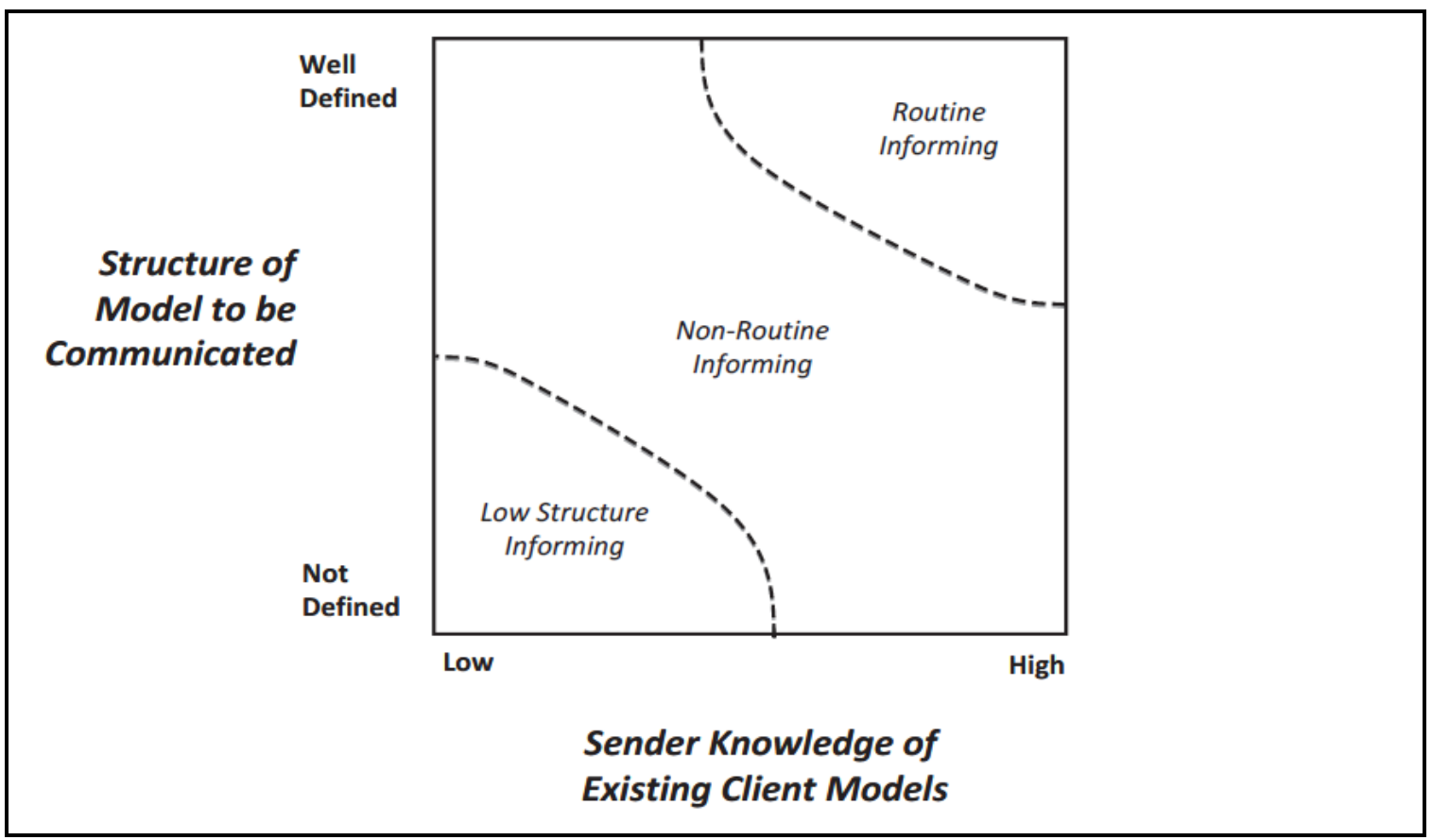

Figure 2 - Structure of Informing Processes (Gill, 2010)

Given this broad understanding of Informing Science, we now shift our focus to the literature related to communication, before considering the communication-related aspects of IT project risk.

\section{Communication}

Communication in organizations has been a prevalent topic for many years due to its importance in work processes. Tirumala and Giri (2009) emphasized communication as "the essence of organizational activity," as well as one of the basic processes at the core of all other functions. In the past, the major concern was generally the effectiveness of communication; however, with the growth of technology, computer-mediated communication (CMC) introduced a myriad of new aspects to consider. Daft and Lewin (1993) understood these new forms of communication could potentially increase the effectiveness of information, making it both "widely disseminated and freely available." Additionally, changes to organizational communication were inevitable in part due to an increasing need for collaboration over distance (Kraut, Fussell, Brennan, \& Siegel, 2002). Thus, the new supply of computer-mediated communication formats was able to meet the new demand for communication media that would facilitate distance communication. 
Research has shown that virtual team communication has advantages and disadvantages over traditional communication. Nydeggar and Nydeggar (2010) referred to the efficiency of virtual group communication as an advantage because it allowed people all over the world to connect at any time. They indicated additional advantages could be found in text-based CMC, which they found to be more complete and complex. However, disadvantages were found in difficulties with relational communication and trust (Nydegger \& Nydegger, 2010). Relational communication and trust both relate to "knowledge of the client" from the routine/non-routine Informing Science framework. Other research by Andres (2006) indicated the mode of communication, whether computer-mediated or face-to-face, has an indirect effect on at least two aspects of team dynamics, team productivity and individual satisfaction with team processes. The face-to-face mode is most often used by co-located traditional teams and the computer-mediated mode is most often used by distributed virtual teams, out of necessity since face-to-face communication may not be possible or practical. Brandt, England, and Ward (2011) indicated communication was a critical success factor for virtual teams and a key difference between virtual teams and traditional teams. More specifically, they found tools and/or technologies to be key communication issues for virtual teams, as well as the "rules of engagement". In summary, they felt overall what worked well for virtual teams did not necessarily work well for co-located teams (Brandt et al., 2011). Finally, although there are differences in communication between virtual and co-located teams, Berry (2011) believed it was dangerous to compare virtual communication channels and face-to-face communication by examining effectiveness and outcome alone. Instead, he suggested the lack of social relationship may be advantageous in improving the task focus and lead to superior task quality results (Berry, 2011).

These concepts from the literature regarding tools and technologies are consistent with the routine/non-routine framework and observations by Gill and Cohen (2008) on technology and media channels. "Routine informing systems tend to converge toward dedicated technologies and channels; non-routine systems tend to spread out across technologies and channels" (Gill \& Cohen, 2009). Initially, traditional IT projects communicated via well-established channels and technologies such as face-to-face communication, written reports and conference calls. Virtual projects began with some of these same established tools such as phone conferences but over time have branched out to a wide range of technologies and channels such as web or video conferencing, e-mail and blogs to name a few. With the emergence of new communication methods, researchers predicted it would be extremely important to update traditional communication theories to accompany new communication possibilities (Daft \& Lewin, 1993). Two dominant theories that emerged to fill this gap are Media Richness theory and Social Presence theory, both of which we describe in the ensuing paragraphs.

\section{Media Richness theory}

Media Richness theory can be used to explore the most effective mode or environment for work tasks that require communication. Sheer and Chen (2004) defined media richness theory as the degree of richness measured by the quantity and quality of four attributes: 1) instant feedback, 2) multiple cues such as voice inflection and body language, 3 ) communication of a wide variety of concepts and ideas with natural language, and 4) personal focus of the medium. The choice of media often follows general guidelines. Rich media are used for complex tasks, while lean media are used for simple tasks. Additionally, researchers have found that informers have been shown to select media based on the content or complexity of the communication (Sheer \& Chen, 2004). The emphasis on complex versus simple tasks relates to the structural complexity of the communicated message and resonates with observations by Gill that "the structure of routine informing systems tends to be driven by the task being performed; non-routine systems are organizationally situated and their structure cannot be predicted or explained without understanding the broader environment and the community of users" (Gill \& Cohen, 2009). We believe, for non-routine 
systems such as virtual IT projects, this observation emphasizes the importance of the environment and differences in the client in a relatively unfamiliar arena (virtual); these are aspects of client knowledge in the routine/non-routine framework. Hence, the virtual project environment must be better understood, along with the additional media channels that come with it. Each of these aspects has a role in determining the "mental mind" model of the client. The mental model of the client goes beyond this to include the client's past experiences, knowledge, and psychology.

Table 1 was generated by analyzing the work of Hamblen (2009), Kroenke (2010), Malhotra and Majchrzak (2005), and Robb (2002). It shows the two types of modes or environments generally discussed in the literature: traditional environments, where workers are co-located, and virtual environments, where at least some members of a team are located at a distance. There is much overlap in the two environments in terms of the types of communication media available, particularly since traditional teams generally have access to most of the technologies available to virtual teams. However, the primary mode in a traditional IT project is face-to-face communication, either one-on-one or in-person meetings and telephone conversations. On the other hand, the primary mode in a virtual IT project is computer mediated communication (CMC), which is conducted via media such as e-mail, bulletin boards, instant messaging, document sharing, and videoconferencing. As Table 1 shows, the most common means of traditional project communication are not available in a virtual environment.

\section{Table 1 - Communication Mediums by Likely Type of Environment}

\begin{tabular}{|l|l|l|}
\hline \multirow{2}{*}{ MEDIA } & \multicolumn{2}{l|}{ ENVIRONMENT } \\
\cline { 2 - 3 } & Traditional & Virtual \\
\hline One-on-one face-to-face interactions & $\sqrt{ }$ & - \\
\hline Face-to-face meetings & $\sqrt{ }$ & - \\
\hline $\begin{array}{l}\text { Hand-written text/reports, not shared in one reposi- } \\
\text { tory }\end{array}$ & $\sqrt{ }$ & - \\
\hline Email & $\sqrt{ }$ & $\sqrt{ }$ \\
\hline Telephone & $\sqrt{ }$ & $\sqrt{ }$ \\
\hline Memos & $\sqrt{ }$ & $\sqrt{ }$ \\
\hline Bulletin Boards & $\sqrt{ }$ & $\sqrt{ }$ \\
\hline Instant Messaging & $\sqrt{ }$ & $\sqrt{ }$ \\
\hline Document Sharing & $\sqrt{ }$ & $\sqrt{ }$ \\
\hline Videoconferencing & - & $\sqrt{ }$ \\
\hline Web Conferencing & - & $\sqrt{ }$ \\
\hline Configuration Management/Version Control & $\sqrt{ }$ & $\sqrt{ }$ \\
\hline Content Management & $\sqrt{ }$ & $\sqrt{ }$ \\
\hline Shared Calendar & $\sqrt{ }$ & $\sqrt{ }$ \\
\hline Blogs/Wikis & $\sqrt{ }$ & $\sqrt{ }$ \\
\hline
\end{tabular}

As Table 1 demonstrates, videoconferencing and Web conferencing are unlikely when team members are traditionally co-located. Similarly, hand-written notes or reports are possible, but less likely to be used by virtual teams. In fact, in today's environment, it is unlikely that handwritten reports are even used on traditional teams, where instead reports can be created on a computer using a variety of different software and then shared by a project team in a single repository. Even some communication media that are listed for both environments are likely to be used far more in one environment than in the other. In particular, virtual teams are dependent on CMC and rely far more heavily on electronic communication than traditional, co-located teams. For example, when a detail needs to be communicated, a traditional team member may simply walk 
over to another team member's cubicle to share the news. However, when teams are dispersed geographically, then a minimum of an email must be employed.

Researchers debate whether the degree of communication effectiveness is dependent on communication mode, i.e., computer-mediated or face-to-face; however, there is no clear consensus (Andres, 2006; Kraut et al., 2002; Tirumala \& Giri, 2009). In Media Richness theory, the richest and most preferred mode of communication has been thought to be face-to-face (Sheer \& Chen, 2004). However, some recent research has found many advantages to computer-mediated communication (Berry, 2011; Kraut et al., 2002; Tirumala \& Giri, 2009). One advantage for many types of CMC is the elimination of the need for communicating parties to be available synchronously. Scheduling issues, which are inevitable when team members are geographically distributed and reside in different time zones, can be eliminated by using media such as e-mail, voicemail, blogs, message boards, and recorded video conferences (Kraut et al., 2002). Another more tacit advantage of CMC involves the combination of the exchange of information and the personality type of the informer and/or the client, which can result in a freer exchange of ideas. Some researchers feel CMC reduces organizational barriers because it is less formal and may even encourage the exchange of information that would not be shared through the traditional mediums (Tirumala \& Giri, 2009). This line of reasoning is based on the logic that software developers sometimes tend to be more introverted and consequently less comfortable with face-to-face communication. At the same time, these technical workers are often very knowledgeable and comfortable with CMC tools, where they may have a level of expertise and where they can remain partially invisible. Over time, some researchers have come to believe CMC has enormous potential. Daft and Lewin (1993) stated electronic communication would "fuel the growth and effectiveness of organizations." Tirumala and Giri (2009) viewed the media used in CMC as important tools for a variety of communication categories, such as "sharing, discussing, and negotiating knowledge" through the use of computer networks. In other words, CMC can offer benefits not necessarily available with face-to-face communication, hence, theoretically fueling the increasing popularity of CMC over face-to-face communication.

\section{Social Presence theory}

While Media Richness theory emphasizes the communication mode, Social Presence theory (SPT) focuses on the sense of intimacy and immediacy of the communication. According to Keil and Johnson (2002), Social Presence theory as defined by Short, Williams, and Christie (1976), considers the level of client awareness and team communication that the media makes possible. For instance, aspects that are present in face-to-face communication such as eye contact, and other non-verbal cues generally lead to a higher social presence. Short et al. (1976) hypothesized the degree of social presence that exists in the communication medium must be taken into consideration to ensure the right interaction is achieved (Keil \& Johnson, 2002). This concept aligns with knowledge of the client's mental model in the routine/non-routine framework (Gill, 2010). In their research, Keil and Johnson (2002) concluded voice mail sent over the Internet was perceived to have a higher social presence than text-based e-mail. Andres (2006) in his research using virtual teams and video-conferencing found the communication medium was important in the support of software development. He determined the medium for distributed teams must be capable of supporting the team communication and collaboration process (Andres, 2006). Since virtual teams have access to a greater number of media choices, they must be aware of the social presence level associated with each medium in order to select the most appropriate one.

Andres (2006) extended Social Presence theory and the idea of degree of social presence. He included the connection between the type of communication channel and the number of communication channels that could be invoked by team members for transmission of "rich information." In $\mathrm{CMC}$, certain aspects such as emotion and nonverbal cues are related to the degree of social 
presence and help us to understand the effectiveness of communication in a virtual environment. It is possible to achieve a high degree of social presence in virtual environments when using video conferencing as the communication medium. This medium can be richer than other forms of CMC because it includes important features such as verbal cues, facial expressions, gaze gestures, and posture which are often only found in face to face communication. Andres (2006) used Social Presence theory when looking at communication processes within the team; however, it must be noted that distributed teams were partially distributed with sub-groups being both colocated and dispersed. He found there were differences between face-to-face and distributed teams in areas such as team collective behaviors and team wide information exchanges. For instance, face-to-face teams demonstrated superior team productivity and worked collectively better than distributed teams using CMC. He also determined the communication medium, in fact, had influence on the quality of information exchange (Andres, 2006).

In summary, several researchers have explored how the Media Richness and Social Presence theories are applied differently in the traditional face-to-face and virtual distributed group environments (Andres, 2006; Keil \& Johnson, 2002; Sheer \& Chen, 2004; Tirumala \& Giri, 2009). Media Richness theory and Social Presence theory both reveal aspects of effective communication that are dependent on the communication medium or channel, suggesting this medium should be selected based on the type of communication being exchanged, i.e., complex versus simple and based on the desired affect or reaction on the client side. From a routine/non-routine viewpoint, Gill \& Cohen (2008) indicated, "routine informing systems tend to support task performance and efficiency; non-routine systems best support a need for adaptability." In other words, the type of communication exchanged is likely related to task complexity on traditional and virtual IT projects, while the desired affect or reaction is more aligned with adaptability, a feature that is a greater issue with non-routine virtual IT projects.

Finally, both theories shed light on the importance of various aspects of communication, such as the environment and the surrounding verbal and non-verbal cues that we take for granted in faceto-face communication and that must somehow be duplicated effectively in computer-mediated communication. We must also realize computer-mediated communication has some advantages of its own that are not present in face-to-face communication, such as the resulting efficiency and clarity from a high percentage of communication being documented and allowing for unlimited review. These advantages may or may not make up for what is lacking in the richness or the level of social presence of the communication.

\section{Information Technology Project Risk}

Having explored both the two major Informing Science models and the two major Communication theories as they relate to communication channels, we now focus our attention on a particular domain, IT project risk. We will first examine what is known about such risk in two different environments, traditional and virtual, before exploring how research into such risk can deepen and expand our understanding of Informing Science.

\section{Traditional projects}

The seminal research on project risk focused on traditional projects and identified the top risk factors and top risk categories. Boehm (1991) identified the top ten risk factors as follows: personnel shortfalls, unrealistic schedules and budgets, developing the wrong functions and properties, developing the wrong user interface, goldplating, continuing stream of requirements changes, shortfalls in externally furnished components, shortfalls in externally performed tasks, real-time performance shortfalls, and straining computer-science capabilities. Although, he did not directly mention communication in this list, it can be implied that communication issues played a role in the cause of these issues such as developing the wrong functions and properties 
or user interfaces. Barki, Rivard, and Talbo (1993) identified the following five risk dimensions which each contained a set of risk factors: technological newness, application size, expertise, application complexity, and organizational environment. Again, communication was not explicitly mentioned; however, risk factors within organizational environment are likely related to communication issues such as extent of changes, intensity of conflicts, and lack of clarity of role definitions. Keil, Lyytinen, and Schmidt (1998) identified the following list of the top eleven risk factors: lack of top management commitment to the project, failure to gain user commitment, misunderstanding the requirements, lack of adequate user involvement, failure to manage end user expectations, changing scope / objectives, lack of required knowledge/skills in the project personnel, lack of frozen requirements, introduction of new technology, insufficient/inappropriate staffing, and conflict between user departments. From this list, we can infer communication issues may have contributed to risks such as misunderstanding the requirements and failure to manage end user involvement. Finally, Wallace (1999) mapped a list of fifty-three risk factors into the following four quadrants: customer mandate, scope and requirements, environment, and execution. Two communication risks are directly listed among the fifty-three risk factors: ineffective communication and team communication issues (Wallace, 1999; Wallace \& Keil, 2004).

\section{Comparing virtual and traditional project risk}

Only one set of researchers has attempted to identify virtual project risk. Reed and Knight (2011) surveyed 154 project management practitioners about project risks and the degree of impact they had on the successful completion of their IT projects. Participants answered based on a recent project they managed and rated a list of 55 risk factors to indicate if each risk had a minor impact, major impact, or no impact at all on a specific project. Of the participants, 107 answered based on a virtual software development project while 47 participants answered based on a traditional co-located software development project. Table 2 shows those risks that rated highest for each of the two categories of projects.

As Table 2 indicates, Reed and Knight (2011) identified two top critical risk factors in the traditional environment: Lack of/or Inadequate Communication and Project Critical to the Organization. Notably, the top critical risk factor in the traditional environment was communication, with a major impact of $55 \%$. These results validate the importance of the communication process and informing in a traditional project environment. The results of this same risk factor in a virtual environment were surprising. First, the same communication risk was not rated the top critical risk factor in a virtual environment and the "major impact" level was significantly lower than for traditional projects. Perhaps communication effectiveness in the virtual environment is more likely to be facilitated by the multiple new communication media/channels introduced by computer mediated communication. Recent research has revealed many advantages of CMC, as discussed in the communications background section above. In any case, these results lead us to conclude that the nature of either the environment (virtual or traditional) or the channel (CMC or not) is a key portion of the Informing Science Communications framework and worthy of further consideration.

The second top critical risk factor in a traditional environment involved the criticality of the project to the organization as a whole. Surprisingly, the percentage of impact on the project was very similar in traditional and virtual project environments. The closeness of these results was unanticipated because it is reasonable to expect it to be more difficult to determine how critical a project is to an organization in a virtual environment. In a face-to-face or co-located environment non-verbal cues are available to help team members understand the importance of their project, but these same cues typically are missing or greatly reduced in a virtual environment. In a traditional project, environmental happenings, such as the increased presence of senior executives can alert the team to the importance of the project. Even recognition of the project in organizational 
meetings would be a cue not necessarily evident to remote workers. Finally, politics of an organization are often more subtle and thus more difficult to identify for remote workers who cannot see behaviors in the office. Reed and Knight's (2011) results indicate that it is possible for virtual project participants to overcome the disadvantage of missing cues, and that this is likely done through increased use of CMC.

Table 2. Major risk factors on traditional and virtual projects (Reed \& Knight, 2011)

\begin{tabular}{|c|c|c|c|}
\hline & \begin{tabular}{|l|} 
Traditional \\
Co-located \\
Project \\
Team \\
\end{tabular} & \begin{tabular}{|l} 
Virtual \\
Project \\
Team \\
\end{tabular} & Conclusion \\
\hline \multicolumn{4}{|c|}{ Lack of or inadequate communication } \\
\hline Major impact & $55 \%$ & $41 \%$ & \multirow{3}{*}{$\begin{array}{l}\text { Lack of or inadequate communication is } \\
\text { a significantly greater problem on } \\
\text { traditional projects than on virtual }\end{array}$} \\
\hline Minor impact & $28 \%$ & $38 \%$ & \\
\hline No impact or did not occur & $17 \%$ & $21 \%$ & \\
\hline \multicolumn{4}{|l|}{ Project critical to organization } \\
\hline Major impact & $43 \%$ & $45 \%$ & \multirow{3}{*}{$\begin{array}{l}\text { Project critical to organization is an } \\
\text { equally significant risk to traditional anc } \\
\text { virtual project teams }\end{array}$} \\
\hline Minor impact & $34 \%$ & $33 \%$ & \\
\hline No impact or did not occur & $23 \%$ & $22 \%$ & \\
\hline \multicolumn{4}{|c|}{ Complex integration of components } \\
\hline Major impact & & $40 \%$ & \multirow{3}{*}{$\begin{array}{l}\text { Complex integration of components is a } \\
\text { major risk for virtual projects but not for } \\
\text { traditional projects }\end{array}$} \\
\hline Minor impact & & $42 \%$ & \\
\hline No impact or did not occur & & $18 \%$ & \\
\hline
\end{tabular}

As we have seen, the top two critical risk factors are identical for virtual and traditional project teams. However, an additional risk factor was identified by Reed and Knight (2011) as critical on virtual projects. This risk factor focuses on the integration of complex project components. As noted earlier, Sheer and Chen (2004) found managers used rich media for complex topics and lean media for simple topics. Since this risk focuses on both complex components and integration which is complex in itself, the Reed and Knight (2011) results appear consistent with Sheer's suggestion that the leaner CMC communication media does not appear to be as effective with complex exchanges of information as the more personal face-to-face communication.

\section{Expanding the Informing Science Model}

As noted earlier, the goal of this paper is to expand understanding of the role of the medium or communication channel in the Informing Science framework by examining one particular domain, that of IT project management communications. We now apply this domain-specific knowledge to the more general traditional Informing Science framework.

\section{Application of Knowledge of the IT Project Management Domain}

The Reed and Knight (2011) study found that lack of or inadequate communication is a more serious risk on traditional projects, where there is a heavier reliance on face-to-face communication, than on virtual projects. This finding suggests that even when face-to-face communication is available, computer mediated communication is preferable when relaying detailed factual information. CMC offers the advantages of lessening the role of social relationships, as suggested by Berry (2011) and provides the option of a permanent and readily available record of the communication, as noted by Reed and Knight (2011). On the other hand, Reed and Knight's finding that 
complex integration of components poses a greater challenge on virtual projects suggests that face-to-face is the preferred communication approach when communicating complex material. This conclusion is further supported by the work of Sheer and Chen (2004) and Gill and Cohen (2008) as it relates to structural complexity. In addition to conveying complexity, face-to-face communication may also be used to build trust, as suggested by Nydegger and Nydegger (2010). Thus, we can draw conclusions about the relationship between the type of communication and the type of media or channel most well-suited, by melding together the research from IT project management, communication, and Informing Science. The conclusions are summarized in Table 3. When reviewing this table, note that the available choices of communication media, combined with the informer's bias with respect to various options, also can play a major role in the choice of communication channel.

Table 3. Choice of communication channel type

\begin{tabular}{|l|l|l|}
\hline Purpose of communication & Face-to-face & $\begin{array}{l}\text { Computer Medi- } \\
\text { ated }\end{array}$ \\
\hline Build trust & Advantage & \\
\hline Develop social relationships & Advantage & \\
\hline Communicate complex material & Advantage & \\
\hline Communicate detailed factual material & & Advantage \\
\hline Avoid interference by social relationships & & Advantage \\
\hline Make permanent record readily available & & Advantage \\
\hline
\end{tabular}

\section{Channel-Impact Model of Informing Science}

Combining the information in Table 3 with the traditional Informing Science model in Figure 1 yields an updated Informing Science model. As shown in Figure 3, the new Channel Impact Model of Informing Science recognizes that face-to-face communications channels work best for building trust or social relationships or for conveying complexity. On the other hand, Computer Mediated Communications work best for conveying specific facts and details. By incorporating these elements into the traditional Informing Science model, we are expanding the traditional model to include consideration of both of Gill's dimensions for complex informing, complexity of the knowledge being communicated, and knowledge of the client's mental models. We do not claim our new model to represent a complete bridging of the gap between the two prior Informing Science models for routine and complex informing. Certainly further work on the informer and client portions of the traditional model would build an even stronger bridge. Nonetheless, in our Channel Impact Model of Informing Science, we have lessened the gap between the traditional Informing Science model in Figure 1 and Gill's model for governing complex, non-routine communications in Figure 2, by merging significant portions of Gill's key concepts into the traditional model. 


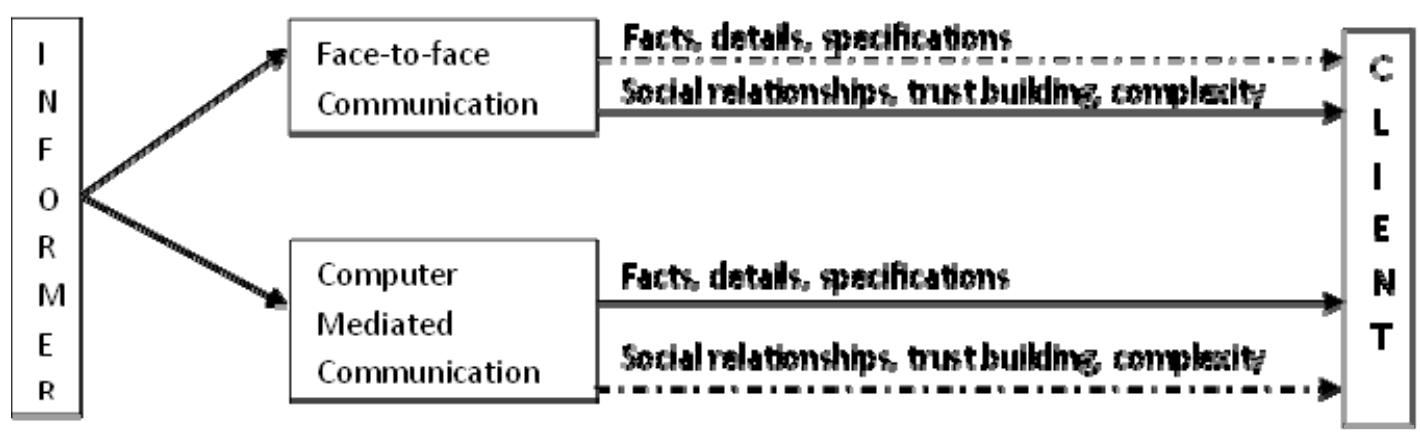

Figure 3. Channel Impact Model of Informing Science

As Figure 3 indicates, when we combine the communication and Informing Science literature with specific research into the domain of IT project risk, it becomes clear that informers should carefully consider the effect of the channel type's filtering on their message. However, there is no evidence that this actually happens in practice. As Cohen (2009) noted, the informer is influenced by his or her own "human limitations in perception and processing," as well as biases from "prior knowledge, skills and abilities". We suggest the informer is also affected by his/her own preferences for how information is delivered, in this case, either using traditional modes or computer meditated communication vehicles. The client, on the receiving end is often affected in the same way as the informer by his/her human limitations. In other words, the information needs of each individual, both informer and client, can be different and they can differ in ways that are not apparent. Those needs are dependent on the "context, environment, social or job role or task, and the individual's psychology" (Cohen, 2009). Thus, while the Channel Impact Model of Informing Science may make the choice of communication media appear visually straightforward, it is not straightforward in practice.

\section{Application of the Channel Impact Model of Informing Science}

For a discussion of the practical implications of the Channel Impact Model, we return to the domain of IT project management. One environmental limitation involves the development of team relationships and the impact of media richness during that process. In general, a traditional IT project where the project team is co-located involves a single primary informer: the project manager. This informer normally meets all project team members face-to-face, which can facilitate the development of a relationship of trust and provide a high degree of social presence and high level of media richness. On the other hand, in a virtual IT project where the project team members are not co-located, the project manager may or may not have the opportunity to meet all project team members face-to-face, and, if they do meet, this meeting may occur a minimal number of times, often only once. In such a situation, relationship and trust development is often a slower process, the degree of social presence is not high and the level of media richness is similarly low. Characteristics of the sender and client as well as relationships and trust can be seen as aspects of the "sender knowledge of the existing client model" dimension in the routine/non-routine framework by Gill (2010). Introductions in the non-routine arena of a virtual environment can take place through various CMC media, like e-mail, blogs, video conferencing, or instant messaging, which may improve the social presence and media richness levels as they relate to relationships. However, as we have seen, these media are not optimal for the development of relationships. Further, the limitation of the informer's comfort level with CMC introductions is dependent on the individual informer. One further item worth noting is that when complex tasks require complex information to be communicated and face-to-face communication is not available, then caution must be exercised to ensure quality communication. One way to do this is by adding feed- 
back loops to ensure that the message being sent by the informer is indeed the message that is being received.

Yet another complexity has to do with the fact that in a project, there typically are multiple clients to inform. These include the project team members and any stakeholders, i.e., end-users, consultants, project sponsor, executives, vendors, other project managers, support staff, and customers etc. (Schwalbe, 2011). These clients may be co-located, or they may reside in different cities, states, and/or countries. To complicate matters further, they may not have access to the same communication media and their background, skills, and biases may differ; hence, the sender's knowledge of the client's mental model could be multiplied by a potentially large number of clients.

While in any project team, the project manager and/or team leads take the leadership role in terms of communication, any team member can fill the role of informer and most team members do fill this role at some point in a project. Project managers/leaders may have an advantage over team members if they have been trained in project management practices, including effective communication, and they may be more accustomed to project based work and developing relationships with a new team for each project. This opens the possibility that when those without this background act as informers, as may be the case with technical leads, channel choices may not be maximized. This possibility and ways to overcome it is a topic for future study.

The concept of matching the channel to the type of communication also needs to take into account communications that have multiple goals. Consider the Channel Impact Model of Informing Science in light of the dilemma of a project manager who seeks to build trusting social relationships, clearly a complex task, at the start of a new project, while at the same time conveying detailed specifications, a more routine task, to team members. Plainly this project manager would be well advised to use both face-to-face communications and computer mediated communications. For virtual projects where face-to-face communication is limited or unavailable, he or she may want to design and implement a particular CMC program specifically for the purpose of developing team relationships.

\section{Conclusion}

We have used the domain of Information Technology project management risk to provide insights into Informing Science, in this case particularly related to the communication channel. We believe a rich field for future Informing Science research lies in the examination of communication on IT projects. These projects are an ideal research domain for Informing Science because project team members often have little or no prior work history together and, thus, little or no preexisting social relationships or communication experience with one another.

As we have demonstrated, the Communication, Informing Science and IT Project management literature, when taken as a whole, supports the concept that communication can be improved by matching the channel to both the type of communication and the complexity of the message. Specifically, communications aimed at building social relationships and trust are best served by face-to-face communications, while more lean knowledge transfer involving facts and detailed specifications is best relayed using computer mediated communications. Unfortunately, research findings are one thing and practical applications are quite another. In reality, channel selection often is based primarily on other factors, such as available media and/or the skills, abilities, and personal biases of the informer. Further, when multiple clients with differing backgrounds and information needs all must be informed, the amount of client knowledge the sender must investigate can become overwhelming. In these cases, computer mediated communication encourages a quick and easy one-size-fits-all approach that likely will not result in the highest quality message 
being received by all clients, since all clients are unlikely to have the same personalities, styles, or skills.

By examining the domain of project management risk, we have demonstrated that the informer's choice of channel can have a direct and substantial impact on the effectiveness of his or her communicated message. The channel is not only a means of communicating the message, but also a filter, with the ability to distort or weaken that message. The Channel Impact Model of Informing Science proposed here modifies the traditional Informing Science model to show the relative impact of the informer's channel choice in filtering different types of communications. In doing so, it highlights considerations for informers to reflect upon when selecting communication media. Perhaps more importantly, it incorporates portions of Gill's concept of complexity into the traditional Informing Science model, thus partially bridging the gap between that traditional Informing Science model and Gill's model for complex, non-routine informing. Notably, we have looked here at only one aspect of the traditional model, the channel, and only one domain, IT project management. It is likely that future researchers looking at the informer or client aspects of the model, or examining other domains will be able to bring the two Informing Science models even closer together.

\section{References}

Andres, H. P. (2006). The impact of communication medium on virtual team group process. Information Resources Management Journal, 19(2), 1-17.

Barki, H., Rivard, S., \& Talbot, J. (1993). Towards an assessment of software development risk. Journal of Management Information Systems, 10(2), 203-225.

Berry, G. (2011). Enhancing effectivness on virtual teams: Understanding why traditional team skills are insufficient. Journal of Business Communication, 48(2), 186-206.

Birdsall, W. F. (2009). The role of the client in informing science: To be informed and to inform. Informing Science: The International Journal of an Emerging Transdiscipline, 12, 147-157. Retrieved from http://www.inform.nu/Articles/Vol12/ISJv12p147-157Birdsall535.pdf

Boehm, B. (1991, January). Software risk management: Principles and practices. IEEE Software, 32-41.

Brandt, V., England, W., \& Ward, S. (2011). Virtual teams. Research Technology Management, 54(6), 6263.

Cash, J., McFaran, F., \& McKenney, J. (1988). Corporate information systems management: The issues facing senior executives (2nd ed.). Homewood, IL: Irwin.

Cohen, E. B. (2009). A philosophy of informing science. Informing Science: The International Journal of an Emerging Transdiscipline, 12, 1-15. Retrieved from http://www.inform.nu/Articles/Vol12/ISJv12p001-015Cohen399.pdf

Daft, R. L., \& Lewin, A. Y. (1993). Where are the theories for the new organizational forms? . Organization Science, 4, i-vi.

Gill, T. G. (2010). Informing business: Research and education on a rugged landscape. Santa Rosa, CA: Informing Science Press.

Gill, T. G., \& Bhattacherjee, A. (2007). The informing sciences at a crossroads: The role of the client. Informing Science: The International Journal of an Emerging Transdiscipline, 10, 17-39. Retrieved from http://inform.nu/Articles/Vol10/ISJv10p017-039Gill317.pdf

Gill, T.G., \& Cohen, E. (2008). Research themes in complex informing. Informing Science: The International Journal of an Emerging Transdiscipline, 11, 147-164. Retrieved from http://www.inform.nu/Articles/Vol11/ISJv11p147-164GillIntro.pdf

Gill, T. G., \& Cohen, E. (2009). Foundations of informing science: 1999-2008. Santa Rosa, CA: Informing Science Press. 
Gill, T.G., \& Hicks, R. C. (2006). Task complexity and informing science: A synthesis. Informing Science: The International Journal of an Emerging Transdiscipline, 9, 1-30. Retrieved from http://www.inform.nu/Articles/Vol9/v9p001-030Gill46.pdf

Hamblen, M. (2009, 10 14). Collaboration tools worth the investment, survey says. Retrieved March 16, 2012, from InfoWorld.com: http://www.infoworld.com/d/mobilize/collaboration-tools-worthinvestment-survey-says-000

Keil, M., \& Johnson, R. (2002). Feedback channels: Using social presence theory to compare voice mail to e-mail. Journal of Information Systems Education, 13(4), 295-302.

Keil, M., Lyytinen, P., \& Schmidt, R. (1998). A framework for identifying software project risks. Communications of the ACM, 41(11), 76-83.

Knight, L. V., Steinbach, T. A., \& Hop, J. (2012). Informing science and andragogy: A conceptual scheme of client-side barriers to informing university students. Informing Science: The International Journal of an Emerging Transdiscipline, 15, 121-145. Retrieved from http://www.inform.nu/Articles/Vol15/ISJv15p121-145Knight0615.pdf

Kraut, R. E., Fussell, S. R., Brennan, S. E., \& Siegel, J. (2002). Understanding effects of proximity on collaboration: Implications for technologies to support remote collaborative work. In P. Hinds \& S. Kiesler, Distributed work (pp. 137-162). Cambridge, MA: MIT Press.

Kroenke, D. (2010). Experiencing MIS (2nd ed.). UpperSaddle River, NJ: Pearson Education.

Malhotra, A., \& Majchrzak, A. (2005). Virtual workspace technologies. MIT Sloan Management Review, 46(2), 11-14.

Nydegger, R., \& Nydegger, L. (2010). Challenges in managing virtual teams. Journal of Business \& Economics Research, 8(3), 69-82.

Project Management Institute. (2008). A guide to the project management body of knowledge (PMBOK) (4th ed.). Newtown Square, PA: Project Management Institute.

Reed, A. H., \& Knight, L. V. (2011). Major virtual project risk factors. Journal of Information Technology Management, 22(4), 1-12.

Robb, D. (2002). Collaboration gets it together. Computerworld, 36(50), 29-30.

Schwalbe, K. (2011). Information technology project management (revised 6th ed.). Boston, MA: Course Technology, Cengage Learning.

Sheer, V. C., \& Chen, L. (2004). Improving media richness theory: A study of interaction goals, message valence, and task complexity in manager-subordinate communication. Management Communication Quarterly, 18(1), 76-93.

Short, J., Williams, E., \& Christie, B. (1976). The social psychology of telecommunications. Great Britain: John Wiley \& Sons, Ltd.

Tirumala, S., \& Giri, V. N. (2009). Analyzing computer-mediated communication and organizational effectiveness. The Review of Communication, 9(1), 100-109.

Wallace, L. (1999). The development of an instrument to measure software project risk. Atlanta, GA: Georgia State University College of Business.

Wallace, L., \& Keil, M. (2004). Software project risks and their effect on outcomes. Communications of the $A C M, 47(4), 68-73$. 


\section{Biographies}

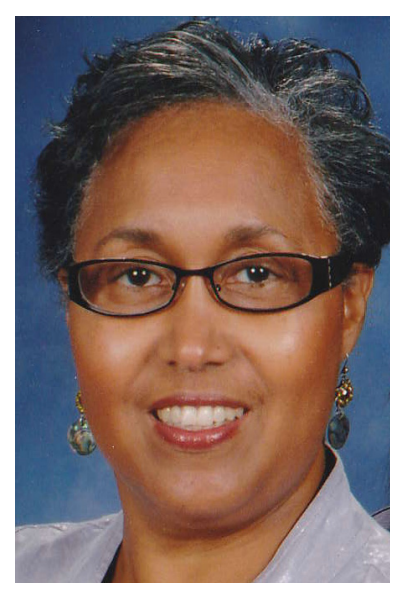

April H. Reed, PhD is an Assistant Professor in the College of Business, Management Information Systems department at East Carolina University. She conducts research in the area of IS/IT project management. She is also a PMI certified Project Management Professional (PMP) and has held industry positions as a Systems Analyst and an IT Project Manager. She has published regularly on the topic of risk and virtual software development projects in IS journals and conferences. She holds a PhD from DePaul University as well as an MBA in MIS and a Bachelor's degree in Computer Science.

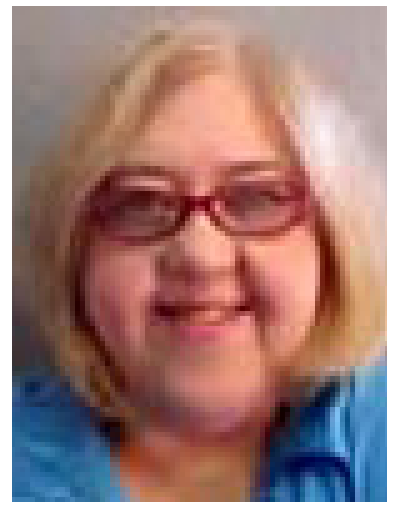

Linda V. Knight, $\mathrm{PhD}$, teaches and conducts research in the area of Information Technology project management, IT leadership, and IT security. Editor-in-Chief of the Journal of Information Technology Education, she is also former Associate Editor of the Information Resources Management Journal, as well as Past President and Fellow of the Society for the Advancement of Information Systems, an affiliate of MBAA International. She has served on the Editorial Advisory Board of the Journal of Cases on Information Technology, and as a member of the Information Resources Management Association Executive Council. A Fellow of the Informing Science Institute, she also served 5 years on MBAA International's Executive Board, including a term as President. An entrepreneur and IT consultant, she has held industry positions in IT management and quality assurance management, and served over seven years as Associate Dean. In addition to a Ph.D. from DePaul University, she holds an MBA and a bachelor's degree in mathematics, both from Dominican University. 